\title{
Prevalence of asthma-chronic obstructive pulmonary disease overlap in patients with airflow limitation
}

\author{
Ahmed Youssef Shabaan ${ }^{1}$, Rasha Galal Daabis ${ }^{1}$, Ahmed Mohamed Abdelhady ${ }^{1 *}$ (D) and Dina Hassan Ibrahim²
}

\begin{abstract}
Background: Asthma-COPD overlap (ACO) according to GINA and GOLD is not a single disease and is described by persistent airflow limitation with several features usually associated with asthma and several features usually associated with COPD. Some different protocols were proposed to diagnose ACO, besides those reported in GINA and GOLD guidelines. Despite the discrepancy between all the proposed diagnostic protocols, the diagnosis of ACO is still worthy as it may lead to a more appropriate treatment plan. In Egypt, prevalence of ACO is hardly estimated due to lack of database of patients. Our aim of work was to detect the prevalence of ACO in patients diagnosed as having a chronic airflow limiting disease.

Results: In asthma group (75 patients), 53.3\% (40 patients) were diagnosed as ACO with 3 statistically significant favoring diagnostic criteria; post-BDR test FEV1/FVC $<70 \%$, longer disease duration, and sputum neutrophilia $\geq$ $57 \%$. While in COPD group (75 patients), 42.7\% (32 patients) were diagnosed as ACO with four statistically significant favoring diagnostic criteria; higher BDR, presence of personal history of either asthma or atopy and sputum eosinophils $>1 \%$.
\end{abstract}

Conclusions: ACO has an underestimated prevalence among those diagnosed with either asthma or COPD. More consensus guidelines are needed to focus on the more effective and the more practical criteria to diagnose such hidden disease.

Keywords: Asthma, COPD, ACO

\section{Background}

Asthma-COPD overlap (ACO) according to GINA and GOLD is not a single disease, and is described by persistent airflow limitation with several features usually associated with asthma and several features usually associated with COPD $[1,2]$. Factors that tend to increase probability of ACO in asthmatic patients include old age (as elderly asthmatic patients usually show more features of fixed obstruction and more severe symptoms $[3,4]$ ) and being a current smoker (as smoking leads to a decline in FEV1 of $66 \mathrm{ml} /$ year in men and $52 \mathrm{ml} /$ year

\footnotetext{
*Correspondence: drahmedhady@gmail.com

${ }^{1}$ Chest Diseases Department, Faculty of Medicine, Alexandria University, Alexandria, Egypt

Full list of author information is available at the end of the article
}

in women and leads to an increased risk of airway remodeling) [5, 6]. While factors that tent to increase probability of ACO in COPD patients include history of atopy (that is associated with elevated total IgE) [7], increase sputum and/or blood eosinophilia [7], and a slightly increased nitric oxide level [8].

Some different protocols were proposed to diagnose ACO [9-16], besides those reported in GINA and GOLD guidelines [1, 2]. Despite the discrepancy between all those protocols, the diagnosis of ACO is still worthy as it may lead to a more appropriate treatment plan. For example, in asthmatic patients with overlap, adding long acting $\mathrm{B}_{2}$ agonist or long acting antimuscarinic is more beneficial and can prevent the side effects of high doses of corticosteroids [17]. On the

\section{Springer Open}

(c) The Author(s). 2021 Open Access This article is licensed under a Creative Commons Attribution 4.0 International License, which permits use, sharing, adaptation, distribution and reproduction in any medium or format, as long as you give appropriate credit to the original author(s) and the source, provide a link to the Creative Commons licence, and indicate if changes were made. The images or other third party material in this article are included in the article's Creative Commons licence, unless indicated otherwise in a credit line to the material. If material is not included in the article's Creative Commons licence and your intended use is not permitted by statutory regulation or exceeds the permitted use, you will need to obtain permission directly from the copyright holder. To view a copy of this licence, visit http://creativecommons.org/licenses/by/4.0/. 
contrary, adding inhaled corticosteroid treatment in COPD patients newly diagnosed as ACO offers a greater clinical and spirometric response [18].

The reported prevalence of ACO varies greatly between 15 and $55 \%$ of patients with chronic airways disease, due to the different diagnostic criteria used and the different population, it ranges between $1.6 \%$ and $4.5 \%$ in general population studies and up to $27 \%$ and $33 \%$ among asthma and COPD populations, respectively [19, 20]. In Egypt, prevalence of ACO is hardly estimated due to lack of database of patients. In 2018, out of 56 patients attending Kasr Al Aini outpatient clinic who were diagnosed as having obstructive airway diseases, 23 (41.1\%) patients were diagnosed as ACO [21]. In this study, we aimed at detecting the prevalence of ACO in patients diagnosed as having a chronic airflow limiting disease.

\section{Methods}

This prospective non-interventional study was done between May and September 2019. We included 150 patients from Alexandria Main University Hospital and $\mathrm{Al}$ Maamora Chest Hospital. Based on sample size calculation done in the statistics department of Alexandria Medicine Faculty, we aimed to assess 75 patients diagnosed as asthma (according to GINA guidelines [1]) and another 75 patients diagnosed as COPD (according to GOLD guidelines [2]) with the exclusion of patients aged below 18 years, having any other respiratory diseases (as interstitial lung disease, obstructive sleep apnea, bronchiectasis, cardiogenic pulmonary congestion and pneumonia) or refused to give a written informed consent. In all procedures, we strictly followed the faculty ethics committee standards.

In the two groups, group I (asthma patients) and group II (COPD patients), every patient was subjected to the following: (1) history taking and clinical assessment, (2) plain X-ray and computed tomography of the chest (to exclude other respiratory diseases), (3) spirometry, forced vital capacity (FVC) procedure, and bronchodilator reversibility test (BDR) that were done according to ATS/ERS task force standards [22] (using either Chest Graph HI-701 in Alexandria Main University hospital or MIR spirolab III in Al Maamora Chest hospital), (4) sputum neutrophil counting in group I, (5) sputum eosinophil counting in group II, and (6) peripheral blood eosinophil and total IgE levels in group II.

BDR was done either by giving four separate puffs (total dose $400 \mathrm{mg}$ ) of salbutamol using metered dose inhaler (MDI) through a spacer, which were delivered at $30 \mathrm{~s}$ intervals or by using salbutamol nebulizer solution $5 \mathrm{mg}$. A lower dose (200 mg of salbutamol MDI or 2.5 $\mathrm{mg}$ of salbutamol nebulizer solution) can be used if there is concern about any effect on the patient's heart rate or tremor. Then, the same maneuver of FVC was repeated 10-15 min later [22-24]. If there was improvement in FEV1 $\geq 200 \mathrm{ml}$ and $\geq 12 \%$, the test was considered positive (considerable BDR). If the improvement was $\geq 400$ $\mathrm{ml}$ and $\geq 15 \%$, the test was considered very positive (high BDR). Finally, if the improvement was less than $200 \mathrm{ml}$ or $12 \%$, it was considered as negative test [2224].

Diagnosis of ACO in group I was dependent on presence post-BDR test FEV1/FVC $<70 \%$ plus one of the following criteria: (1) adult-onset asthma (above 40 years), (2) history of smoking with pack/year index $\geq 10$, (3) history of exposure to respiratory irritants such as industrial dusts and chemical fumes, (4) long-term asthma since childhood, (5) chronic mucus hypersecretion, and (6) neutrophilia in sputum [15]. While in group II, diagnosis of $\mathrm{ACO}$ was dependent on presence of 2 major criteria or 1 major and 2 minor criteria of the following: major criteria of (1) high BDR on at least two occasions, (2) eosinophilia in sputum and/or peripheral eosinophilia in blood $\geq 300 / \mathrm{ml}$, (3) personal history of asthma (prior to 40 years of age) and minor criteria of (1) elevated serum total $\mathrm{IgE} \geq 100 \mathrm{UI} / \mathrm{ml}$, (2) history of atopy, and (3) considerable BDR on at least two occasions [16]. Neutrophils $\geq 57 \%$ in sputum was considered positive for neutrophilia while eosinophils $\geq 1 \%$ was considered positive for eosinophilia [25].

The statistical analysis was done using IBM SPSS software package version 20.0. (Armonk, NY: IBM Corp.). Qualitative data were described using number and percent. The Kolmogorov-Smirnov test was used to verify the normality of distribution. Quantitative data were described using range (minimum and maximum), mean, standard deviation, and median. Significance of the obtained results was judged at the 5\% level. The used statistical tests included (1) chi-square test for categorical variables to compare between different groups, (2) Fisher's exact correction for chi-square when more than $20 \%$ of the cells have expected count less than 5, (3) Student's $t$ test for normally distributed quantitative variables to compare between two studied groups, and (4) MannWhitney test for abnormally distributed quantitative variables to compare between two studied groups.

\section{Results}

In group I, 53.3\% of patients were diagnosed as ACO. Three statistically significant favoring diagnostic criteria for ACO in asthma patients were found, namely postBDR test FEV1/FVC $<70 \%$, longer disease duration, and sputum neutrophilia $\geq 57 \%$. While other criteria (age, gender, late onset of the disease after age of 40, history of smoking, exposure to irritant, and chronic mucus production) had no statistically significant difference 
between patients retaining their asthma diagnosis and those evolved to ACO diagnosis (Table 1).

In group II, $42.7 \%$ of patients were diagnosed as ACO. Four statistically significant favoring diagnostic criteria for $\mathrm{ACO}$ were found in COPD patients, namely higher $\mathrm{BDR}$, presence of personal history of either asthma or atopy and sputum eosinophils $>1 \%$. While other criteria (age, gender, IgE level, and peripheral eosinophil count) had no statistically significant difference between patients retaining their COPD diagnosis and those evolved to ACO diagnosis (Table 2).

\section{Discussion}

The prevalence of ACO considerably varies among different published studies. This may be due to different studied populations and different diagnostic criteria. A systematic research was performed in ISI Web of Knowledge, MEDLINE/PubMed, and Scopus databases up to 30 May 2019 to identify studies reporting the prevalence of ACO among patients with asthma and COPD that was reported in 19 and 22 studies, respectively. These values showed marked variability in patients with asthma (ranging from 3.2 to 51.4\%) and COPD (ranging from 13.0 to $55.7 \%$ ) [26]. Sevimli et al. showed that among 2742 patients initially screened, 338 were diagnosed as asthma, ACO was determined in 40/338 (11.8\%) [27]. Menezes and his colleagues included a total of 767 patients with asthma were classified as asthma, COPD, and $\mathrm{ACO}$ at the estimated ratios of $1.7 \%, 12 \%$, and $1.8 \%$, respectively [28]. In the study by de Oca et al., the rate of $\mathrm{ACO}$ in the overall population was reported as $5.3 \%$ in cases with a previous asthma diagnosis and as $2.3 \%$ in cases newly diagnosed during the study [29]. In another review by Wurst et al., the frequency of $\mathrm{ACO}$ was reported as $12.1-55.2 \%$ in patients with COPD and as $13.3-61 \%$ in patients with asthma [30]. According to other reports, the prevalence of ACO among COPD patients ranged from 3.3 to $54.6 \%$ [19, 31, 32].

In our study, the mean age of the cases of $\mathrm{ACO}$ was $45.80 \pm 14.62$ years that was higher as compared with the cases of asthma (41.29 \pm 11.57 years), but it did not reach a statistically significant value. Sevimli et al. reported that the mean age of the cases of ACO was 63.78 \pm 10.23 years that was statistically significantly higher as compared with the cases of asthma $(p=0.001)$ [27]. Moreover, the prevalence of ACO was reported to vary according to the age group as shown in the study by De Marco et al., who reported that prevalence of ACO in 8360 patients with asthma was determined as $16 \%$ at age $20-44$ years, $30 \%$ at age $45-64$ years, and $61 \%$ at age 65-84 years [19]. This also agreed with Al Halfawy et al., who found that patients who were diagnosed as having $\mathrm{ACO}$ were older than asthmatic patients with mean age of $53.43 \pm 11.06$ and $42.62 \pm 11.11$ years [21]. It is thought that the increase in the incidence of $\mathrm{ACO}$ at an older age compared with asthma could be explained by increased airway remodeling, biomass exposure, and development of fixed airflow limitation due to the burden of smoking in addition to the age-related decline in FEV1 [12, 33, 34].

In this study, the median duration of the disease in the cases of ACO was 24.5 years with range between 20 and

Table 1 Patients characteristics in group I

\begin{tabular}{|c|c|c|c|c|}
\hline & $\begin{array}{l}\text { Total } \\
(n=75)\end{array}$ & $\begin{array}{l}\text { Asthma } \\
(n=35,46.7 \%)\end{array}$ & $\begin{array}{l}\text { ACO } \\
(n=40,53.3 \%)\end{array}$ & $\overline{p \text { value }}$ \\
\hline Age (mean in years) & $43.69 \pm 13.39$ & $41.29 \pm 11.57$ & $45.80 \pm 14.62$ & 0.146 \\
\hline Gender; & & & & 0.355 \\
\hline Male & 47 & 20 & 27 & \\
\hline Female & 28 & 15 & 13 & \\
\hline Post-BDR FEV1/FVC $<70 \%$ & & & & $<0.001 *$ \\
\hline Yes & 40 & 0 & 40 & \\
\hline No & 35 & 35 & 0 & \\
\hline Onset after age of 40 & 11 & 6 & 5 & 0.571 \\
\hline History of smoking & 35 & 14 & 21 & 0.279 \\
\hline Exposure to irritant & 23 & 9 & 14 & 0.384 \\
\hline Duration of disease (median in years) & 23.0 & 20.0 & 24.50 & $0.006^{*}$ \\
\hline Chronic mucus & 18 & 7 & 11 & 0.448 \\
\hline Sputum neutrophils & & & & $0.037^{*}$ \\
\hline$<57 \%$ & 24 & 15 & 9 & \\
\hline$\geq 57 \%$ & 7 & 1 & 6 & \\
\hline
\end{tabular}

ACO asthma-COPD overlap, Post-BDR post-bronchodilator reversibility test, FEV1 forced expiratory volume in 1st second, FVC forced vital capacity * Statistically significant at $p \leq 0.05$ 
Table 2 Patients characteristics in group II

\begin{tabular}{|c|c|c|c|c|}
\hline & $\begin{array}{l}\text { Total } \\
(n=75)\end{array}$ & $\begin{array}{l}\text { COPD } \\
(n=43,57.3 \%)\end{array}$ & $\begin{array}{l}\text { ACO } \\
(n=32,42.7 \%)\end{array}$ & $p$ value \\
\hline Age (mean in years) & $57.19 \pm 10.05$ & $57.30 \pm 8.41$ & $57.03 \pm 12.05$ & 0.914 \\
\hline Gender & & & & 0.717 \\
\hline Male & 67 & 39 & 28 & \\
\hline Female & 8 & 4 & 4 & \\
\hline $\mathrm{BDR}$ & & & & $<0.001^{*}$ \\
\hline No & 50 & 40 & 10 & \\
\hline Considerable & 16 & 3 & 13 & \\
\hline High & 9 & 0 & 9 & \\
\hline Personal history of asthma & 31 & 12 & 19 & $0.006^{*}$ \\
\hline Personal history of atopy & 16 & 5 & 11 & $0.017^{*}$ \\
\hline Sputum eosinophils & & & & $0.001 *$ \\
\hline$<1 \%$ & 36 & 27 & 9 & \\
\hline$>1 \%$ & 12 & 2 & 10 & \\
\hline Peripheral eosinophils & & & & 0.067 \\
\hline$<300 / \mathrm{ml}$ & 63 & 39 & 24 & \\
\hline$\geq 300 / \mathrm{ml}$ & 12 & 4 & 8 & \\
\hline lgE level & & & & 0.055 \\
\hline$<100 \mathrm{UI} / \mathrm{ml}$ & 33 & 23 & 10 & \\
\hline$\geq 100 \mathrm{UI} / \mathrm{ml}$ & 42 & 20 & 22 & \\
\hline
\end{tabular}

$A C O$ asthma-COPD overlap, $B D R$ bronchodilator reversibility test

*Statistically significant at $p \leq 0.05$

40 years that was statistically significantly higher as compared with the cases of asthma alone (median 20 years with range between 17.5 and 33 years). However, Sevimli et al. showed that there was no statistically significant difference in the duration of disease between cases with $\mathrm{ACO}$ and cases with asthma alone in the cases included in their study [27].

Despite that history of smoking in the asthma group was less likely encountered than in the ACO group (40\% vs. $52.5 \%)$, this finding was not statistically significant. $\mathrm{Al}$ Halfawy et al. showed that $87 \%$ of ACO group and only $23 \%$ of asthma group were either current or ex-smokers [21]. Fu et al. also found that most asthmatic patients in their study were never smokers whereas $71.4 \%$ in the ACO group were ex-smokers [35].

Neutrophillia $>57 \%$ of sputum was presented in 1 (6.3\%) of our asthmatic patients and in $6(40 \%)$ of ACO patients which is statistically significant $(p=0.037)$. This came in accordance with Gao et al., who showed that $80.5 \%$ of the cases with ACO had high sputum neutrophil count vs $71.09 \%$ in cases with asthma [36].

The diagnostic value of bronchodilator responsiveness (BDR) in ACO is unclear. A "significant" BDR (most often considered to be a $12 \%$ and $200 \mathrm{~mL}$ improvement in FEV1 or FVC following bronchodilator) [37] does not reliably differentiate asthma from COPD [38].
Furthermore, up to half of COPD patients can exhibit a significant BDR [39], with considerable variability over time [40]. According to the majority of current criteria, the presence of BDR is supportive but not essential to diagnosis of ACO [41]. In our study, we followed the Spanish guidelines in considering irreversible airway obstruction, defined as post-BDR test FEV1/FVC $<70 \%$, as the basic first step to diagnose ACO in asthmatics [15]. While in our COPD patients, we found that high or considerable BDR (see "Methods" section) was a statistically significant diagnostic criteria of ACO. This came in agreement with Toledo-Pons et al., who showed that no COPD cases showed highly positive BDR vs $9.7 \%$ in ACO cases. They also reported that $15.5 \%$ of the cases with COPD showed positive BDR as compared with $23 \%$ in the cases with ACO [42]. Song et al., also reported that only a small proportion of COPD patients had bronchodilator responsiveness $>400 \mathrm{~mL}$ [43].

In this study, the mean age of the cases of COPD alone was slightly higher as compared with the cases of ACO, but this did not reach a statistically significant value. Many authors have reported that ACO patients were younger than COPD patients [21, 44-48], while others found no significant difference regarding age of patients of both groups [49-51]. 
We found history of either asthma or atopy in COPD patients as statistically significant favoring factors for diagnosing ACO. Gelb et al. suggested that ACO may begin with asthma and that Th2 inflammation from recurrent exacerbations could lead to neutrophil elastase production and lung tissue destruction [52]. ToledoPons et al. showed that there was a statistically significant difference in the history of atopy (allergic rhinitis) between the ACO cases (12.7\%) as compared with cases COPD alone $(6.8 \%)(p=0.021)$ [42]. Kitaguchi et al. found that the prevalence of allergic rhinitis was significantly higher in ACO, and they stated that the most accessible marker of the Th2 type of inflammation is increased concentrations of blood eosinophils, and consistently, blood and sputum eosinophil counts are significantly higher in patients with ACO compared with COPD [53]. Yamamura et al. reported also that the peripheral blood eosinophils are significantly higher in cases with ACO as compared with cases with COPD alone [54]. We could not prove the statistically significant difference in peripheral eosinophilia between $\mathrm{ACO}$ and COPD patients despite the double number of ACO patients who crossed the limit of $300 / \mathrm{ml}$ (8 vs. 4). This may be due to the few overall number of such patients with peripheral eosinophilia.

High IgE level ( $\geq 100 \mathrm{IU} / \mathrm{ml})$ was more frequently encountered in our ACO patients compared to COPD alone patients; however, this difference was not statistically significant. Kobayashi et al. showed that total serum IgE level was significantly higher in patients with ACOS than in those without ACOS $(2989 \mathrm{IU} / \mathrm{mL}$ vs. $451 \mathrm{IU} /$ $\mathrm{mL}, p=0.004)$. The authors also reported that the presence of antigen-specific IgE also was observed more frequently in those with ACOS $(56.8 \%$ vs $28.6 \%, p=0.001)$ [55].

\section{Conclusion}

From all previously mentioned, we can conclude that ACO has an underestimated prevalence among those diagnosed with either asthma or COPD. More consensus guidelines are needed to focus on the more effective and the more practical criteria to diagnose such hidden disease.

\section{Abbreviations}

COPD: Chronic obstructive pulmonary disease; ACO: Asthma-COPD overlap; GINA: Global Initiative for Asthma; GOLD: Global Initiative for Chronic Obstructive Lung Disease; FEV1: Forced expiratory volume in 1st second; IgE: Immunoglobulin E; FVC: Forced vital capacity; ATS: American thoracic society; ERS: European respiratory society; BDR: Bronchodilator reversibility; MDI: Metered dose inhaler

Acknowledgements

Not applicable

\section{Authors' contributions}

AY reviewed the research idea. RA shared in creation of the research idea. AA shared in creation of the research idea, in writing the paper and in the procedures. DH shared in writing the paper and in doing most of the procedures. All authors read and approved the final manuscript.

\section{Funding}

All the procedures were done using Alexandria Medicine Faculty and Al Maamora Chest Hospital resources without any impact of this on the design of the study or collection, analysis, and interpretation of data.

\section{Availability of data and materials}

The datasets used and/or analyzed during the current study are available from the corresponding author on reasonable request.

Ethics approval and consent to participate

Alexandria Medicine Faculty Ethics Committee (IRB No:: 00012098-FWA No.: 00018699) approved this research on 18 April 2019 with the serial number 0105953. A written informed consent was taken from each patient.

\section{Consent for publication}

Not applicable

\section{Competing interests}

The authors declare that they have no competing interests.

\section{Author details}

${ }^{1}$ Chest Diseases Department, Faculty of Medicine, Alexandria University, Alexandria, Egypt. ${ }^{2}$ Al Maamora Chest Hospital, Alexandria, Egypt.

Received: 16 September 2020 Accepted: 2 January 2021

Published online: 13 January 2021

\section{References}

1. Global Initiative for Asthma -GINA 2019, (Available from: https://ginasthma. org/). Accessed 21 Mar 2019

2. Global Initiative for Chronic Obstructive Lung Disease - GOLD 2019, (Available from: https://goldcopd.org/). Accessed 21 Mar 2019.

3. Bumbacea D, Campbell D, Nguyen L, Carr D, Barnes PJ, Robinson D et al (2004) Parameters associated with persistent airflow obstruction in chronic severe asthma. Eur Respir J 24:122-128

4. Vonk JM, Jongepier H, Panhuysen CIM, Schouten JP, Bleecker ER, Postma DS (2003) Risk factors associated with the presence of irreversible airflow limitation and reduced transfer coefficient in patients with asthma after 26 years of follow up. Thorax 58:322-327

5. Spears M, McSharry C, Chaudhuri R, Weir C, de Wet C, Thomson NC (2013) Smoking in asthma is associated with elevated levels of corticosteroid resistant sputum cytokines-an exploratory study. PLoS One 8:e71460

6. Tamimi A, Serdarevic D, Hanania N (2012) The effects of cigarette smoke on airway inflammation in asthma and COPD: therapeutic implications. Respir Med 106:319-328

7. Fabbri LM, Romagnoli M, Corbetta L, Casoni G, Busljetic K, Turato G et al (2003) Differences in airway inflammation in patients with fixed airflow obstruction due to asthma or chronic obstructive pulmonary disease. Am J Respir Crit Care Med 167:418-424

8. Malerba M, Radaeli A, Olivini A, Damiani G, Ragnoli B, Montuschi P et al (2014) Exhaled nitric oxide as a biomarker in COPD and related comorbidities. Biomed Res Int 2014:271918

9. Nielsen M, Barnes CB, Ulrik CS (2015) Clinical characteristics of the asthmaCOPD overlap syndrome - a systematic review. Int J Chron Obstruct Pulmon Dis 10:1443-1454

10. Gibson PG, Simpson JL (2009) The overlap syndrome of asthma and COPD: what are its features and how important is it? Thorax. 64:728-735

11. Kauppi $P$, Kupiainen $H$, Lindqvist $A$, Tammilehto L, Kilpeläinen M, Kinnula VL et al (2011) Overlap syndrome of asthma and COPD predicts low quality of life. J Asthma 48:279-285

12. Zeki A, Schivo M, Chan A, Albertson T, Louie S (2011) The asthma-COPD overlap syndrome: a common clinical problem in the elderly. J Allergy (Cairo) 2011:861926 
13. Alshabanat A, Zafari Z, Albanyan O, Dairi M, FitzGerald JM (2015) Asthma and COPD overlap syndrome (ACOS): a systematic review and metaanalysis. PLoS One 10:e0136065

14. Miravitlles M, Soler-Cataluna JJ, Calle M, Molina J, Almagro P, Quintano JA et al (2013) A new approach to grading and treating COPD based on clinical phenotypes: summary of the Spanish COPD guidelines (GesEPOC). Prim Care Respir J 22:117-121

15. Plaza V, Álvarez F, Calle M, Casanova C, Cosío BG, López-Viña A et al (2017) Consensus on the Asthma-COPD Overlap Syndrome (ACOS) between the spanish COPD Guidelines (GesEPOC) and the Spanish Guidelines on the Management of Asthma (GEMA). Arch Bronconeumol 53:443-449

16. Soler-Cataluña JJ, Cosío B, Izquierdo JL, López-Campos JL et al (2012) Consensus document on the overlap phenotype COPD-asthma in COPD. Arch Bronconeumol 48:331-337

17. Poulos LM, Ampon RD, Marks GB, Reddel HK (2013) Inappropriate prescribing of inhaled corticosteroids: are they being prescribed for respiratory tract infections?A retrospective cohort study. Prim Care Respir J 22:201-208

18. Miravitlles M, Soler-Cataluna JJ, Calle M, Molina J, Almagro P, Quintano JA et al (2017) Spanish COPD Guidelines (GesEPOC) 2017: pharmacological treatment of stable COPD. Arch Bronconeumol 53:324-335

19. de Marco R, Pesce G, Marcon A, Accordini S, Antonicelli L, Bugianiet M et al (2013) The coexistence of asthma and chronic obstructive pulmonary disease (COPD): prevalence and risk factors in young, middle-aged and elderly people from the general population. PLoS One 8:629-635

20. Mannino DM, Gagnon RC, Petty TL, Lydick E (2000) Obstructive lung disease and low lung function in adults in the United States: data from the National Health and Nutrition Examination Survey. Arch Intern Med 160:1683-1689

21. Al Halfawy A, Abdelhafiz H, Kamal E, Gaber M (2018) Characteristic features and percentage of asthma chronic obstructive pulmonary disease overlap among patients with obstructive airway diseases. Egypt J Chest Dis Tuberc 67:356-360

22. Miller MR, Hankinson J, Brusasco V, Burgos F, Casaburi R, Coates A, Crapo R et al (2005) ATS/ERS task force : Standardisation of spirometry. Eur Respir J 26:319-338

23. Stoller JK, Basheda S, Laskowski D, Goormastic M, McCarthy K (1993) Trial of standard versus modified expiration to achieve end-of-test spirometry criteria. Am Rev Respir Dis 148:275-280

24. Swanney MP, Jensen RL, Crichton DA, Beckert LE, Cardno LA, Crapo RO (2000) FEV(6) is an acceptable surrogate for FVC in the spirometric diagnosis of airway obstruction and restriction. Am J Respir Crit Care Med 162:917919

25. Belda J, Leigh R, Parameswaran K, O'Byrne PM, Sears MR, Hargreave FE (2000) Induced Sputum Cell Counts in Healthy Adults. Am J Respir Crit Care Med 161:475-478

26. Mendy A, Forno E, Niyonsenga T, Carnahan R, Gasana J (2018) Prevalence and features of asthma-COPD overlap in the United States 2007-2012. Clin Respir J 12:12917-12920

27. Sevimli N, Yapar D, Türktaş H (2019) The Prevalence of Asthma-COPD Overlap (ACO) among patients with asthma. Turk Thorac J 20:97-102

28. Menezes AMB, de Oca MM, Pérez-Padilla R, Nadeau G, Wehrmeister FC, Lopez-Varela MV et al (2014) Increased risk of exacerbation and hospitalization in subjects with an overlap phenotype: COPD-asthma. Chest 145:297-294

29. de Oca MM, Varela MVL, Laucho-Contreras ME, Casas A, Schiavi E, Mora JC (2017) Asthma-COPD overlap syndrome (ACOS) in primary care of four Latin America countries: the PUMA study. BMC Pulm Med 17:69-75

30. Wurst KE, Kelly-Reif K, Bushnell GA, Pascoe S, Barnes N (2016) Understanding asthma-chronic obstructive pulmonary disease overlap syndrome. Respir Med 110:1-11

31. Sin DD, Miravitlles M, Mannino DM, Soriano JB, Price D, Celli BR et al (2016) What is asthma- COPD overlap syndrome? Towards a consensus definition from a round table discussion. Eur Respir J 48:664-673

32. Mannino DM (2005) "Haeso cheonsik" and chronic obstructive pulmonary disease in Korea. Am J Respir Crit Care Med 172:795-810

33. Wang L, Gao S, Zhu W, Su J (2014) Risk factors for persistent airflow limitation: analysis of 306 patients with asthma. Pak J Med Sci 30:1393-1350

34. Ding B, DiBonaventura M, Karlsson N, Ling X (2016) Asthma-chronic obstructive pulmonary disease overlap syndrome in the urban Chinese population: prevalence and disease burden using the 2010, 2012, and 2013
China National Health and Wellness Surveys. Int J Chron Obstruct Pulmon Dis 11:1139-1154

35. J-j F, McDonald VM, Gibson PG, Simpson JL (2014) Systemic inflammation in older adults with asthma-COPD overlap syndrome. Allergy, Asthma Immunol Res 6:316-324

36. Gao J, Zhou WT, Chen BD, Lin WM, Wu SF, Wu F (2017) Sputum cell count: biomarkers in the differentiation of asthma, COPD and asthma-COPD overlap. Int J Chron Obstruct Pulmon Dis 12:2703-2710

37. Pellegrino R, Viegi G, Brusasco V, Crapo R, Burgos F, Casaburi R et al (2005) Interpretative strategies for lung function tests. Eur Respir J 26:948-968

38. Gjevre JA, Hurst TS, Taylor-Gjevre RM, Cockcroft DW (2006) The American Thoracic Society's spirometric criteria alone is inadequate in asthma diagnosis. Can Respir J 13:433-437

39. Tashkin D, Celli B, Decramer M, Liu D, Burkhart D, Cassino C et al (2008) Bronchodilator responsiveness in patients with COPD. Eur Respir J 31:742750

40. Albert P, Agusti A, Edwards L, Tal-Singer R, Yates J, Bakke P et al (2012) Bronchodilator responsiveness as a phenotypic characteristic of established chronic obstructive pulmonary disease. Thorax 67:701-708

41. Milne S, Mannino D, Sin DD (2020) Asthma-COPD overlap and chronic airflow obstruction: definitions, management, and unanswered questions. J Allergy Clin Immunol Pract 8:483-495

42. Toledo-Pons N, van Boven JF, Román-Rodríguez M, Pérez N, Valera Felices $J \mathrm{~L}$, Soriano JB et al (2019) ACO: time to move from the description of different phenotypes to the treatable traits. PLoS One 14:915-987

43. Song JH, Lee $\mathrm{C}-\mathrm{H}$, Kim DK, Yoon H, Byun MK, Rhee CK et al (2018) Differences in prevalence of asthma-COPD overlap according to different criteria. Medicine 97:e12049

44. Barrecheguren M, Esquinas C, Miravitlles M (2015) The asthma-chronic obstructive pulmonary disease overlap syndrome (ACOS): opportunities and challenges. Curr Opin Pulm Med 21:74-79

45. de Marco R, Marcon A, Rossi A, Antó JM, Cerveri I, Gislason T et al (2015) Asthma, COPD and overlap syndrome: a longitudinal study in young European adults. Eur Respir J 46:671-679

46. Diaz-Guzman E, Khosravi M, Mannino DM (2011) Asthma, chronic obstructive pulmonary disease, and mortality in the US population. COPD 8: 400-407

47. van Boven JF, Román-Rodríguez M, Palmer JF, Toledo-Pons N, Cosío BG, Soriano JB (2016) Comorbidome, pattern, and impact of asthma-COPD overlap syndrome in real life. Chest 149:1011-1020

48. Ekerljung L, Mincheva R, Hagstad S, Bjerg A, Telg G, Stratelis G et al (2018) Prevalence, clinical characteristics and morbidity of the Asthma-COPD overlap in a general population sample. J Asthma 55:461-469

49. Vas Fragoso CA, Murphy TE, Agogo GO, Allore HG, McAvay GJ (2017) Asthma-COPD overlap syndrome in the US: a prospective population-based analysis of patient-reported outcomes and health care utilization. Int J Chron Obstruct Pulmon Dis 12:517-527

50. Sorino C, Pedone C, Scichilone N (2016) Fifteen-year mortality of patients with asthma-COPD overlap syndrome. Eur J Intern Med 34:72-77

51. Cosio BG, Soriano JB, López-Campos JL, Calle-Rubio M, Soler-Cataluna JJ, de-Torres JP, et al. (2016) Defining the asthma-COPD overlap syndrome in a COPD cohort. Chest 149:45-52

52. Gelb AF, Christenson SA, Nadel JA (2016) Understanding the pathophysiology of the asthma-chronic obstructive pulmonary disease overlap syndrome. Curr Opin Pulm Med 22:100-105

53. Kitaguchi Y, Komatsu Y, Fujimoto K, Hanaoka M, Kubo K (2012) Sputum eosinophilia can predict responsiveness to inhaled corticosteroid treatment in patients with overlap syndrome of COPD and asthma. Int J Chron Obstruct Pulmon Dis 7:283-289

54. Yamamura K, Hara J, Kobayashi T, Ohkura N, Abo M, Akasaki K et al (2019) The prevalence and clinical features of asthma-COPD overlap (ACO) definitively diagnosed according to the Japanese Respiratory Society Guidelines for the Management of ACO 2018. J Med Investig 66:157-164

55. Kobayashi S, Hanagama M, Yamanda S, Ishida M, Yanai M (2016) Inflammatory biomarkers in asthma-COPD overlap syndrome. Int J Chron Obstruct Pulmon Dis 11:2117-2123

\section{Publisher's Note}

Springer Nature remains neutral with regard to jurisdictional claims in published maps and institutional affiliations. 